\title{
REAPROVEITAMENTO DA AREIA DE DESMOLDAGEM COMO SUBSTITUTO PARCIAL DA AREIA EM ARTEFA- TOS DE CONCRETO
}

\section{REUSE OF THE MOLDING SAND AS A PARTIAL SUBSTITUTE OF SAND IN CONCRETE ARTIFACTS}

\section{Diogo Fernando Pereira (FURB) \\ Gregory Viegas Zimmer (FURB) \\ Joel Dias da Silva, Dr. (FURB) \\ Renyer Roger Custódio (FURB)}

\section{Palavras Chave \\ Fundição; Areia de Moldagem; Reaproveitamento; Concreto}

\section{Key Words}

Foundry; Molding Sand; Reuse; Concrete

\section{RESUMO}

Objetivou-se, através de um levantamento bibliográfico e ensaios técnicos em laboratório (ensaios de caracterização físico-química, produção de corpos de prova e testes mecânicos de resistência) valorizar a areia de moldagem descartada por uma indústria de fundição no município de Blumenau. Verificou-se que, a areia de moldagem misturada com resinas, dificulta a sua recuperação e reutilização, gerando assim, um grande volume a ser descartado em aterros industriais, e consequentemente, onerando ainda mais o custo de produção. Acrescentam-se ainda determinações legais que forçam a uma diminuição dos volumes a serem descartados e dispostos em aterros industriais, cujos custos para a disposição aumentam continuamente.

\section{ABSTRACT}

A bibliographic survey and technical tests in the laboratory (physical-chemical characterization tests, production of test specimens and mechanical resistance tests) aimed at valuing molding sand discharged by a foundry industry in the City of Blumenau. It was found that molding sand mixed with resins makes it difficult to recover and reuse, thus generating a large volume to be discarded in industrial landfills, and consequently, further burdening the cost of production. There are also legal provisions that force a reduction of the volumes to be disposed of and disposed of in industrial landfills, whose costs for the disposal increase continuously. 


\section{INTRODUÇÃO}

A areia de moldagem corresponde ao maior volume de resíduos gerados no chão de fábrica, contudo, em função do processo adotado, poderá apresentar características quantitativas e qualitativas bem distintas, numa comparação entre diferentes indústrias do mesmo ramo, contendo talvez, metais pesados e/ou resinas poliméricas (PENKAITIS, 2012).

A areia, para fins e aplicações industriais, é composta por areias e quartzitos alterados, com elevado teor de sílica (SiO2), obtidas a partir de sedimentos arenosos, arenitos e quartzitos, com granulometria típica entre 0,5 e $0,1 \mathrm{~mm}$, que resultam da alteração dessas rochas pela ação de agentes intempéricos ou também podem ser produtos de cominuição (COELHO, 2010). Contudo, no processo de obtenção desta areia, um rastro de impactos ambientais é deixado na forma de passivos ambientais, com grandes áreas degradadas pela lavra, o material estéril do capeamento do solo (horizonte A) e lama argilosa.

Fagundes et al., (2012) esclarecem que a inexistência de informações e diretrizes legais quanto ao aproveitamento e valorização da areia de moldagem, em aplicações fora da indústria de fundição, como já acontece em outros países, também contribuem para o aumento deste passivo ambiental em aterros industriais, mesmo quando de sua destinação correta.

Neste sentido, infelizmente, no Brasil já se estimava que, nas últimas décadas, fossem descartadas pelas fundições, cerca de 2 milhões de t.ano-1 de areia contaminada com resinas fenólicas, correspondendo a mais de três quartos do total de resíduos gerados pela Indústria de Fundição (SCHEUNEMANN, 2005). O autor destaca ainda que, mesmo com muitas empresas contando com processos de regeneração mecânica de tais areias, o reaproveitamento destas não ultrapassava os $70 \%$, e dependendo do processo a que as mesmas fossem submetidas, a recuperação não chegaria a $40 \%$. Segundo o Sindicato da Indústria de Fundição do Estado de Minas Gerais, a indústria de fundição mesmo contribuindo para a reciclagem de sucatas metálicas, possui alto potencial poluidor, gerando toneladas de resíduos mensalmente. O aproveitamento de resíduos, principalmente oriundos de fontes não renováveis, torna-se elemento estratégico para a competitividade e a permanência das empresas no mercado (SIFUMG, 2011 p.46).

Relatam-se diversas iniciativas de aproveitamento desta areia, contemplando a recuperação e regeneração da areia no chão de fábrica (OKITA, 2006; BRONDINO;
SILVA; BRONDINO, 2014), a modificação do processo industrial como a substituição de resina fenólica por resina furânica no sistema de moldagem e macharia, por cura a frio, com catalisador de base orgânica (CETESB, 2002), o reaproveitamento de areia de desmoldagem descartada como agregado em misturas asfálticas densas (COUTINHO NETO, 2004), na fabricação de tijolos de solo-cimento (ANGST; VENDRUSCOLO, 2008), e por fim, sua utilização no concreto asfáltico convencional (FENGLER, 2016).

Neste trabalho, em virtude de seus objetivos, dar-se-á atenção especial a recuperação da areia de moldagem descartada, objetivando-se o seu reuso como substituto parcial da areia em artefatos de concreto.

\section{MATERIAIS E MÉTODOS}

\subsection{Origem e Caracterização da Areia de Desmoldagem Descartada}

A areia de desmoldagem descartada foi coletada na empresa Electro Aço Altona, no município de Blumenau, no Setor de Desmoldagem da UPR - Unidade de Produtos Repetitivos, transportada em sacos plásticos até o Laboratório de Tecnologias de Aproveitamento de Materiais da FURB, e armazenada em tambores plásticos de $200 \mathrm{~L}$ até o momento dos ensaios.

Buscou-se efetuar uma caracterização prévia da areia de desmoldagem com o auxílio da NBR 10.004 (ABNT, 2004), que classifica os resíduos de acordo com sua periculosidade. Este procedimento é recomendado porque, dependendo dos materiais envolvidos no processo de fundição, a recuperação e reutilização da areia de moldagem serão dificultadas e o material deverá ser destinado a um aterro industrial. Este ensaio é também parte integrante dos laudos requeridos pela FATMA e FAEMA, que também exigem os resultados de análises químicas do extrato lixiviado e do extrato aquoso, a segregação adequada da areia, que deverá estar presente na política de gerenciamento de seus resíduos, contemplando todas as etapas, "do berço ao túmulo" (BLUMENAU, 2013; SANTA CATARINA, 2014).

Quanto aos ensaios de lixiviação e solubilização da areia de fundição, estes foram conduzidos em duplicata, tendo sido realizados no Laboratório de Ensaios Químicos (EQU/FURB), obedecendo-se os procedimentos elencados nas NBR 10.005 (ABNT, 2004) - Lixiviação de Resíduos - Procedimentos, e NBR 10.006 (ABNT, 2004) - Solubilização de Resíduos Sólidos - Métodos de Ensaios. 
2.2 Determinação da composição granulométrica da areia de moldagem descartada e da brita utilizadas na fabricação de artefatos de concreto não-estrutural

Para a condução desta etapa, foi necessário determinar a composição granulométrica de todos os insumos que serão utilizados na fabricação destes artefatos. Assim, foram seguidos os procedimentos descritos na Norma ABNT NM 248 (ABNT, 2003), que prescreve o método para a determinação da composição granulométrica de agregados miúdos e graúdos para a preparação do concreto.

A execução do ensaio seguiu também as orientações de coleta da amostra de agregado conforme a NM 26 (ABNT, 2000 p.2), que pontua que "as amostras parciais, tomadas em diferentes pontos do lote, devem representar todas as possíveis variações do material, tanto quanto à sua natureza, características, bem como as condições em que é encontrado, podendo assim resultar na porção mais representativa do material".

As amostras foram então remetidas ao Laboratório de Materiais (ECV/FURB), depois de umedecida para evitar segregação e de cuidadosamente misturada, formando duas amostras para o ensaio, conforme Figura 01.

Figura 01: Preparação de amostras para a determinação da composição granulométrica da areia de moldagem descartada

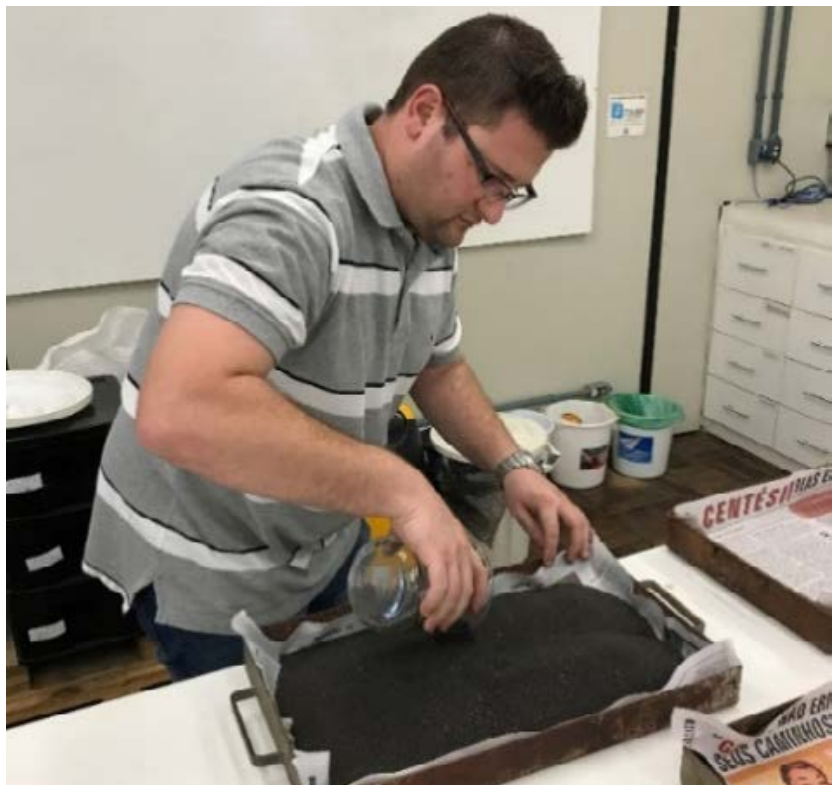

Fonte: Elaborado pelos autores (2016)

Na sequência, já no Laboratório de Materiais, as amostras foram direcionadas à estufa, onde permaneceram durante 24 horas, em temperatura controlada no intervalo de $105 \pm 5^{\circ} \mathrm{C}$, conforme preconizado na norma. Terminado o período de secagem, as amostras foram resfriadas à temperatura ambiente para determinação de suas massas específicas. Para isto, foram utilizadas peneiras, previamente limpas, de modo a formar um único conjunto de peneiras, com abertura de malha em ordem crescente da base para o topo, conforme Figura 02 .

Figura 02: Peneiramento e Classificação da Areia de Desmoldagem

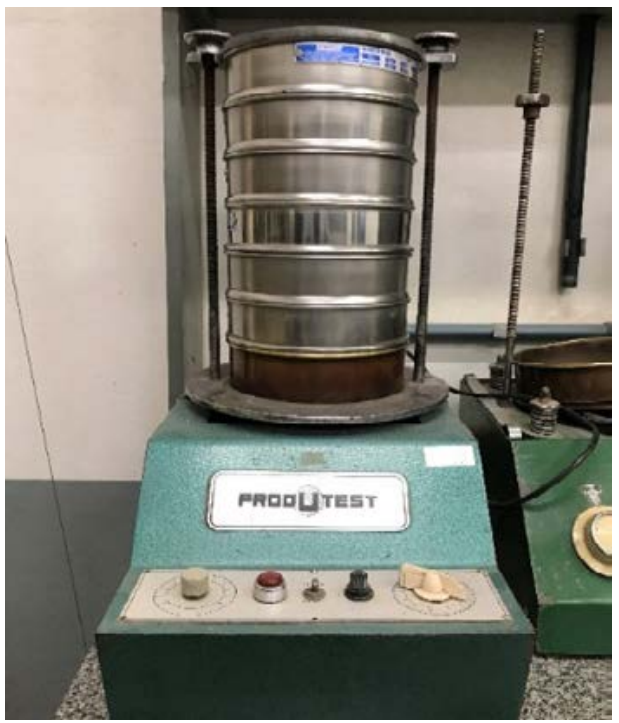

Fonte: Elaborado pelos autores (2016)

O mesmo procedimento foi adotado para a brita zero, utilizada no estudo, para fins de confecção de corpos de prova com a areia de fundição. Contudo, pela sua granulometria, foram adotados equipamentos compatíveis, conforme Figura 03.

Figura 03: Ensaio de determinação da composição granulométrica brita zero

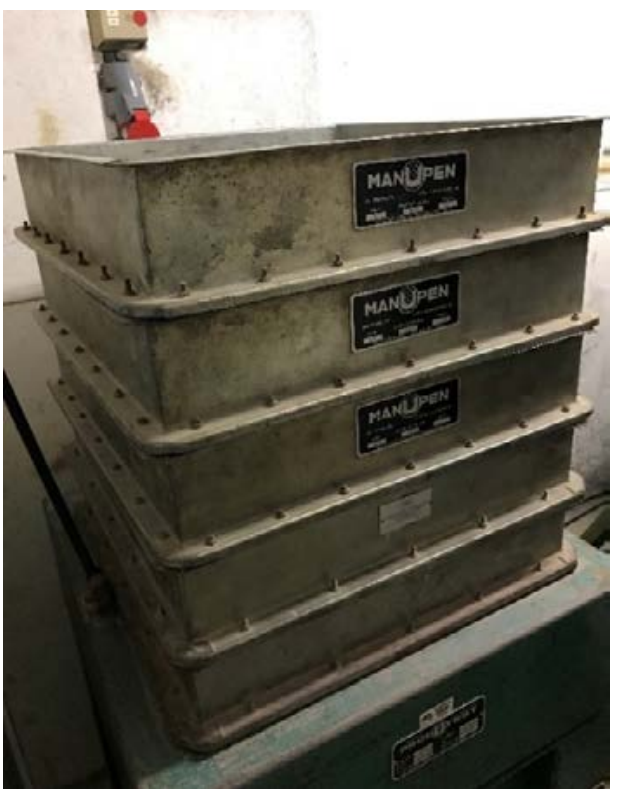

Fonte: Elaborado pelos autores (2016) 
Para cada uma das amostras de ensaio, de acordo com a Norma NBR NM 248, foram calculadas as porcentagens retidas, em massa, em cada peneira, com aproximação de $0,1 \%$. Tomou-se o cuidado de que todas as amostras apresentassem necessariamente a mesma dimensão máxima característica e, nas demais peneiras, os valores de porcentagem retida individualmente não deveriam diferir mais que $4 \%$ entre si.

\subsection{Determinação da massa específica da areia} de fundição e da brita utilizadas no estudo

Nesta etapa, a NBR ABNT 9776 (ABNT, 1987) foi utilizada para a determinação da massa específica de agregados miúdos por meio do frasco Chapman. O ensaio, que utiliza amostras secas em estufa $\left(105^{\circ} \mathrm{C}-110^{\circ} \mathrm{C}\right)$, consiste em se colocar água no frasco Chapman até marca de $200 \mathrm{~cm} 3$, deixando-o em repouso, para que a água aderida às faces internas escorram totalmente; em seguida, com a introdução de $500 \mathrm{~g}$ de agregado miúdo seco no frasco, que deve ser devidamente agitado para eliminação das bolhas de ar. A leitura do nível atingido pela água no gargalo do frasco indica o volume, em $\mathrm{cm} 3$, ocupado pelo conjunto água-agregado miúdo, alertando-se para que as faces internas devam estar completamente secas e sem grãos aderentes.

\section{RESULTADOS}

A partir do referencial teórico e dos resultados obtidos nos ensaios de granulometria e massa específica dos insumos a serem utilizados nos artefatos de concreto, foram definidos os traços e/ou concentrações de areia de moldagem incorporadas no concreto, a saber: $10 \%$, 15\% e $20 \%$ como substituto parcial da areia. Estes testes, assim como os de resistência mecânica e de compressão foram conduzidos no Laboratório de Materiais (ECV/FURB).

A pavimentação feita por blocos de concreto intertravados, também chamados de pavers, tem sua estrutura formada por camadas de revestimento e base sobre o subleito. São capazes de suportar cargas e tensões de contato provocadas pelo tráfego, consequentemente, protegendo a camada de base do desgaste por abrasão. A base é a camada que recebe as tensões distribuídas pelos blocos, e tem a função de proteger estruturalmente o subleito. Os pavers são mais resistentes a carga que outros tipos de pavimento, possuem baixa condutividade térmica e toda vez que é necessário reparar alguma tubulação subterrânea é possível reaproveita-los (CRUZ, 2003; BITTENCOURT, 2012; PURIFICAÇÃO, 2009).

As normas brasileiras que se referem a esse tipo de pavimento são a NBR 9780 "Peças de concreto para pavimentação da resistência à compressão" (ABNT, 1987) e a NBR 9781 "Peças de concreto para a pavimentação" (ABNT, 2013). Em geral, as normas especificam o dimensionamento e a resistência à compressão sem referenciar a idade do pavimento. A NBR 9781 (ABNT, 2013) define parâmetros relacionados às dimensões do bloco, considerando que as variações máximas permissíveis nas dimensões são de $3 \mathrm{~mm}$ no comprimento e largura, e $5 \mathrm{~mm}$ na altura das peças. Essas considerações permitem que os fabricantes possam trabalhar com vários formatos de produto. Já os parâmetros de resistência, apontados pela NBR 9780 (ABNT, 1987) dividem os blocos quanto a finalidade, $35 \mathrm{MPa}$ para solicitações de veículos comerciais e $50 \mathrm{MPa}$ para tráfego de veículos especiais, ou solicitações capazes de produzir grades efeitos de abrasão. Na presente pesquisa, definiu-se 35 Mpa para o parâmetro de resistência.

A Tabelas 01, 02 e 03, apresentam as porcentagens retidas no conjunto de peneiras utilizado no ensaio de granulometria, necessário para definição do traço do concreto a ser utilizado nos corpos de prova.

\begin{tabular}{|c|c|c|c|c|c|}
\hline \multicolumn{2}{|c|}{ Peneiras } & \multicolumn{4}{|c|}{ Granulometria } \\
\hline Número & $\begin{array}{c}\text { Abertura } \\
(\mathrm{mm})\end{array}$ & $\begin{array}{c}\text { Peso } \\
\text { Retido } \\
\text { (g) }\end{array}$ & $\begin{array}{l}\% \text { Peso } \\
\text { Retido } \\
\text { Parcial }\end{array}$ & $\begin{array}{c}\% \text { Retido } \\
\text { Acumulado }\end{array}$ & $\begin{array}{c}\% \\
\text { Passante }\end{array}$ \\
\hline $1.1 / 2^{\prime \prime}$ & 38,1 & 0 & 0 & 0 & 100 \\
\hline $3 / 4^{\prime \prime}$ & 19 & 0 & 0 & 0 & 100 \\
\hline $3 / 8^{\prime \prime}$ & 9,5 & 0 & 0 & 0 & 100 \\
\hline 4 & 4,76 & 0 & 0 & 0 & 100 \\
\hline 8 & 2,38 & 0 & 0 & 0 & 100 \\
\hline 16 & 1,19 & 0,53 & 0,05 & 0,05 & 99,95 \\
\hline 30 & 0,59 & 6,07 & 0,61 & 0,66 & 99,34 \\
\hline 50 & 0,297 & 519 & 52,28 & 52,94 & 47,06 \\
\hline 100 & 0,149 & 430,75 & 43,39 & 96,33 & 3,67 \\
\hline \multirow[t]{3}{*}{200} & 0,075 & 22,29 & 2,25 & 98,58 & 1,42 \\
\hline & Fundo & 14,12 & 1,42 & 100 & 0 \\
\hline & Total & 992,76 & 100 & & \\
\hline
\end{tabular}

Fonte: Elaborado pelos autores (2016) 
Tabela 02: Ensaio granulométrico da areia de grossa.

\begin{tabular}{c|c|c|c|c|c}
\multicolumn{2}{c|}{ Peneiras } & \multicolumn{4}{c}{ Granulometria } \\
\hline Número & $\begin{array}{c}\text { Abertura } \\
\text { (mm) }\end{array}$ & $\begin{array}{c}\text { Peso } \\
\text { Retido } \\
\text { (g) }\end{array}$ & $\begin{array}{c}\text { \% Peso } \\
\text { Retido } \\
\text { Parcial }\end{array}$ & $\begin{array}{c}\text { \% Retido } \\
\text { Acumulado }\end{array}$ & $\begin{array}{c}\% \\
\text { Passante }\end{array}$ \\
\hline $1.1 / 2^{\prime \prime}$ & 38,1 & 0 & 0 & 0 & 100 \\
\hline $3 / 4^{\prime \prime}$ & 19 & 0 & 0 & 0 & 100 \\
\hline $3 / 8^{\prime \prime}$ & 9,5 & 0 & 0 & 0 & 100 \\
\hline 4 & 4,76 & 18,32 & 1,56 & 1,56 & 98,44 \\
\hline 8 & 2,38 & 71,66 & 6,09 & 7,65 & 92,35 \\
\hline 16 & 1,19 & 201,85 & 17,16 & 24,80 & 75,20 \\
\hline 30 & 0,59 & 385,21 & 32,74 & 57,54 & 42,46 \\
\hline 50 & 0,297 & 333,97 & 28,39 & 85,93 & 14,07 \\
\hline 100 & 0,149 & 119,4 & 10,15 & 96,08 & 3,92 \\
\hline 200 & 0,075 & 32,95 & 2,80 & 98,88 & 1,12 \\
\hline \multirow{2}{*}{20} & Fundo & 13,2 & 1,12 & 100 & 0 \\
\cline { 2 - 7 } & Total & 1176,56 & 100 & & \\
\hline
\end{tabular}

Fonte: Elaborado pelos autores (2016)

Tabela 03: Ensaio granulométrico da brita zero

\begin{tabular}{c|c|c|c|c|c|}
\multicolumn{2}{c|}{ Peneiras } & \multicolumn{4}{c|}{ Granulometria } \\
\hline \multirow{2}{*}{ Número } & $\begin{array}{c}\text { Abertura } \\
\text { (mm) }\end{array}$ & $\begin{array}{c}\text { Peso } \\
\text { Retido } \\
\text { (g) }\end{array}$ & $\begin{array}{c}\text { \% Peso } \\
\text { Retido } \\
\text { Parcial }\end{array}$ & $\begin{array}{c}\% \text { Retido } \\
\text { Acumulado }\end{array}$ & $\begin{array}{c}\% \\
\text { Passante }\end{array}$ \\
\hline l" $^{\prime \prime}$ & 25 & 0 & 0 & 0 & 100 \\
\hline $3 / 4^{\prime \prime}$ & 19 & 0 & 0 & 0 & 100 \\
\hline $1 / 2 "$ & 12,7 & 450 & 4,70 & 4,70 & 95,30 \\
\hline $3 / 8 "$ & 9,5 & 2.460 & 25,68 & 30,38 & 69,62 \\
\hline 4 & 4,76 & 6.060 & 63,26 & 93,63 & 6,37 \\
\hline \multirow{2}{*}{3} & Fundo & 610 & 6,37 & 100 & 0 \\
\cline { 2 - 6 } & Total & 9.580 & 100 & & \\
\hline
\end{tabular}

Fonte: Elaborado pelos autores (2016)

O primeiro traço realizado foi aquele que não continha nenhuma porcentagem de areia de moldagem descartada em sua incorporação, garantindo assim que nenhum resquício do material ficasse no misturador e interferisse no experimento, constituindo-se como "amostra branco". Os demais traços utilizados continham 10\%, 15\% e $20 \%$ de areia de moldagem qual substituto parcial da areia lavada, componente essencial da argamassa. Todos os corpos de prova apresentaram resultados satisfatórios quanto aos padrões exigidos pelas diferentes NBRs utilizadas durante a pesquisa, obedecendo-se as informações:

Resistência característica do concreto à compressão (Fck): $35 \mathrm{MPa}$

- Condição de Preparo C - Sd: 0,7

- Areia Grossa: 1,25
- Brita 0: 12,7mm

- CP IV - M.E.A. $(2,95)$ e M.U. $(1,5)$

- Agregado Graúdo - M.E.A (2,69) e M.U. $(1,31)$

- Areia - M.E.A. $(2,62)$ e M.U. $(1,5)$

- Água - M.U. $(1,0)$

- $a-54,326$

- Adensamento Manual - $\mathrm{H}=10,995 \%$

A partir das equações presentes nas NBR avaliadas, tem-se que, o consumo de materiais baseado no cimento será:

- Areia: $409,365 \mathrm{Kg} / \mathrm{m}^{3}$

- Brita: $967,052 \mathrm{Kg} / \mathrm{m}^{3}$

- Água: $232,864 \mathrm{Kg} / \mathrm{m}^{3}$

Os corpos de prova, depois de terminado o seu período de cura de 28 dias, foram então submetidos aos testes mecânicos, onde foi possível avaliar à resistência e a porcentagem de incorporação de areia de moldagem descartada correspondente, conforme Figura 04.

Figura 04: Ensaio de resistência à compressão dos diferentes corpos de prova

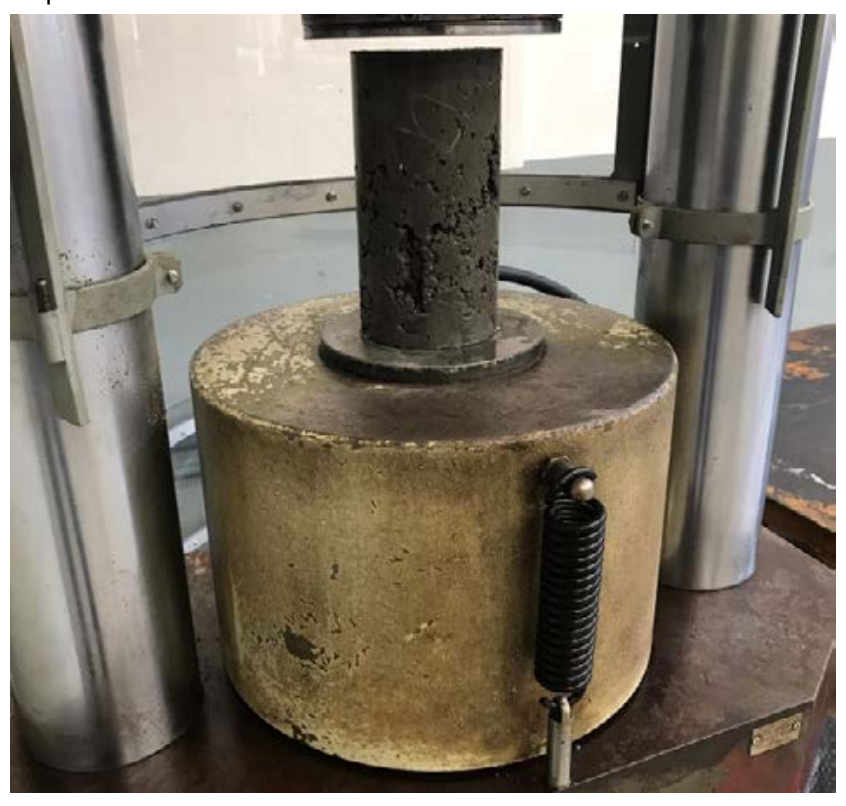

Fonte: Elaborado pelos autores (2016)

A Tabela 04 apresenta as informações referentes à resistência à compressão a que os corpos de prova foram submetidos. 
Tabela 04: Resistência à compressão das amostras com diferentes porcentagens de incorporação

AMOSTRA (resultados em MPa)

\begin{tabular}{c|c|c|c|c}
\hline Corpos de Prova & Branco & $\mathbf{1 0} \%$ & $\mathbf{1 5 \%}$ & $\mathbf{2 0 \%}$ \\
\hline 1 & 33,5 & 39,4 & 40 & 40,6 \\
\hline 2 & 40 & 36,4 & 37 & 37,4 \\
\hline 3 & 34.3 & 37.2 & 38.1 & 38.5 \\
\hline 4 & 36.1 & 37,00 & 36,00 & 38.4 \\
\hline Média & 36,75 & 37,60 & 37,67 & 39,00 \\
\hline DP & 4,60 & 1,59 & 2,08 & 2,26 \\
\hline
\end{tabular}

Fonte: Elaborado pelos autores (2016)

Diante do exposto, percebe-se que, a incorporação de areia de moldagem no traço faz com quem aumente a resistência à compressão, ou seja, quanto maior a porcentagem de incorporação do material no corpo de prova, maior será a resistência final. Todas as amostras com adição da areia de moldagem tiveram resultados superiores em relação a amostra sem acréscimo do resíduo.

É possível afirmar que é viável usar a areia de moldagem descartada qual substituto parcial da areia, uma vez que o resultado dos ensaios de resistência foi superior às resistências do traço sem nenhuma porcentagem de incorporação. Baruffi et al., (2015) e Santos et al., (2016), conseguiram incorporar cerca de $15 \%$ da areia de moldagem em seus experimentos, sendo que o primeiro, utilizou para a fabricação de concreto para pavimentação, enquanto que o segundo, para blocos estruturais de concreto, sempre como substituto parcial de areia.

Importante salientar que, Baruffi et al., (2015) os valores obtidos para o teste de resistência à compressão foram menores do que o estabelecido pela norma NBR 9731 (ABNT, 2013) de $35 \mathrm{Mpa}$, enquanto que, os da presente pesquisa ultrapassaram tal valor, apresentando-se aptos para pavimentos intertravados sujeitos a tráfego leve.

Santos (2015) conseguiu incorporar diferentes faixas de areia de moldagem descartada, chegando ao máximo de $40 \%$ como substituto parcial de areia. Contudo, o autor pontua que todos os outros traços possam ser usados para a fabricação de blocos vazados de concreto, porém, o melhor resultado, segundo ele, é o de $35 \%$ de substituição de areia natural por areia de fundição.

\section{CONCLUSÕES}

Os testes conduzidos mostraram que a areia de desmoldagem descartada pode ser utilizada na construção de blocos de concreto, pois obedeceram às normas referentes a suportar pressão de 35Mpa, contudo, não isenta de testes adicionais voltados para uma possível toxicidade quanto à realização dos testes de solubilização e lixiviação das peças.

\section{REFERÊNCIAS}

ABNT - Associação Brasileira de Normas Técnicas. NBR 9.776, de mar 1987. Agregados - Determinação da massa específica de agregados miúdos por meio do frasco Chapman. Rio de Janeiro, 3 p., 1987.

NM 26, de maio de 2001. Agregados Amostragem. Rio de Janeiro, 10 p., 2001.

NM 248, de julho de 2003. Agregados Determinação da composição granulométrica. Rio de Janeiro, 3 p., 2003.

. NBR 10.004, de 31 de maio de 2004. Resíduos sólidos - Classificação. Rio de Janeiro, 71 p., 2004.

NBR 10.005, de 31 de maio de 2004. Procedimento para obtenção de extrato lixiviado de resíduos sólidos. Rio de Janeiro, 20 p., 2004.

NBR 10.006, de 31 de maio de 2004.

Procedimento para Obtenção de Extrato Solubilizado de Resíduos Sólidos. Rio de Janeiro, 7 p., 2004.

ANGST, M.; VENDRUSCOLO, M. A. Aproveitamento da areia de fundição na produção de tijolos. In: Anais...II Encontro de Sustentabilidade em Projeto do Vale do Itajaí. Disponível em: <http://ensus2008.paginas.ufsc.br/files/2015/09/Aproveitamento-da-areia-defundi\%C3\%A7\%C3\%A3o.pdf>. Acesso em: 12 Abr 2017.

BARUFFI, A. et al. Uso da areia de fundição como substituto parcial da areia natural em blocos de concreto para pavimentação. In: Anais...IV Seminário Nacional de Construções Sustentáveis. Passo Fundo, RS. Disponível em:<https://goo.gl/8czcew >. Acesso em 12 Abr 2017.

BITTENCOURT, S. F. Avaliação da resistência à compressão de pavers produzidos com agregados de resíduos de construção e demolição e areia de fundição. Dissertação. Limeira, São Paulo, 2012.

BRONDINO, O. C.; SILVA, J. P. G.; BRONDINO, N. C. M. O problema do descarte da areia de fundição: 
ensino para o desenvolvimento sustentável. Disponível em: <http://198.136.59.239/ abengeorg/cobenge-2014/ Artigos/129851.pdf>. Acesso em: 16 set. 2015.

CETESB - Companhia Ambiental do Estado de São Paulo. Produção Mais Limpa: Casos de Sucesso. 2002. Disponível em: <http://consumosustentavel.cetesb.sp. gov.br/wp-content/uploads/sites/39/2015/01/caso01. pdf>. Acesso em: 20 Set 2016.

COELHO, J. M. (Consultor). Projeto ESTAL - Projeto de Assistência Técnica ao Setor de Energia. 2010. Disponível em: << https://goo.gl/IWvFQq >>. Acesso em: 20 Set 2016.

COUTINHO NETO, B. Avaliação do reaproveitamento de areia de fundição como agregado em misturas asfálticas. 2014. 293 f. Tese. Disponível em: <http://www. teses.usp.br/teses/disponiveis/18/18137/tde-10022011101639/publico/BeneditoCoutinho.pdf>. Acesso em: 20 Set 2016.

CRUZ, L. O. M. Pavimento intertravado de concreto: estudo dos elementos e métodos de dimensionamento. 2003. 281 f. Dissertação. Disponível em: << http://wwwp. coc.ufrj.br/teses/mestrado/geotecnia/2003/teses/CRUZ_ LOM_03_t_M_geo.pdf >> Acesso em: 20 Set 2016.

\section{ELECTRO AÇO ALTONA. Relatório de} Sustentabilidade. 2014. Disponível em: <http://www2. altona.com.br/web/relatorio-de-sustentabilidade/2014>. Acesso em: 03 set. 2015.

FAEMA - Fundação Municipal do Meio Ambiente. Instrução Normativa IN-009. Março 2013. Blumenau, 2013. Disponível em: <https://goo.gl/sXtt1w> Acesso em 05 Mai 2017.

FAGUNDES, A. B. et al. Caminhos para a Sustentabilidade do Setor de Fundição no Brasil. Revista GEPROS, n. 2, p. 27, 2012.

FATMA - Fundação do Meio Ambiente. Instrução Normativa IN-04. Abril 2014. Florianópolis, 2014. Disponível em: <http://www.sideropolis.sc.gov.br/uploads/273/arquivos/654742_in_04_Atividades_Industriais. pdf $>$. Acesso em 05 Mai 2017.

FENGLER, R. Z et al. Avaliação laboratorial da utilização de areias de fundição no concreto asfáltico convencional. In: Anais... II Prêmio ENEC - Encontro Nacional dos Estudantes de Engenharia Civil, ${ }^{\circ}{ }^{\circ}$ de outubro de 2015, Gramado, RS. Disponível em:<http://enec.fenec.com.br/ wp-content/uploads/2015/01/II-Pr\%C3\%AAmio-ENECSelecionados.pdf>. Acesso em: 15 Mar 2017.

OKITA, J. R. Estudo para minimização e reaproveitamento de resíduos sólidos de fundição. 2006. $137 \mathrm{f}$. Dissertação. Disponível em: <http://www.pg.utfpr.edu. br/dirppg/ppgep/dissertacoes/arquivos/44/Dissertacao. pdf>. Acesso em: 14 Dez 2016.

PENKAITIS, G. Impacto ambiental gerado pela disposição de areias de fundição: Estudo de caso. 2012.92 f. Dissertação. Universidade de São Paulo, São Paulo.2012.

PURIFICAÇÃO, E. B. Estudo do Uso de Agregados Reciclados de Concreto e Substituição do Cimento por Resíduo de Polimento de Porcelana na Produção de Piso Intertravado de Concreto. 2009. 104 f. Disponível em: <http://www.bibliotecadigital.ufmg.br/dspace/bitstream/handle/1843/ISMS-84XLBK/disserta_o_eduardo_ brunopdf.pdf?sequence=1> Acesso em: 15 Mar 2017.

Resolução CONSEMA 011/08. Critérios para a utilização de ADF de materiais ferrosos na produção de concreto asfáltico e artefatos de concreto não estrutural. Secretaria de Estado do Desenvolvimento Econômico Sustentável. Conselho Estadual do Meio Ambiente CONSEMA. Estado de Santa Catarina, 2008, 14p.

SANTOS, C. C. Avaliação das propriedades técnicas de blocos intertravados de concreto produzidos com resíduos de fundição. Joinville, 2015. Disponível em: <https://goo.gl/Dy4Xac>. Acesso em: 24 Abr 2016.

SANTOS, A. V. et al. Reaproveitamento de areia de fundição descartada em substituição da areia natural na fabricação de blocos estruturais de concreto. In: Anais...VII Internation Symposium on Technological Innovation. Aracaju, SE. Disponível em: < http://www.api. org.br/conferences/index.php/ISTI2016/ISTI2016/paper/ viewFile/46/64 >. Acesso em: 24 Abr 2016.

SIFUMG - Sindicato da Indústria de Fundição no Estado de Minas Gerais. Guia de boas práticas do setor de fundição. Belo Horizonte: IEL-MG / SIFUMG, 2011. Disponível em: http://www.sifumg.com.br/wp-content/uploads/2016/02/ cartilha-de-fundicao.pdf>. Acesso em: 05 Nov 2016. 